\title{
Fixed rate of blood component improves the survival rate of patients in massive transfusion
}

\author{
WEN-TING WANG $^{1 *}$, YONG-HUA ZHAN ${ }^{2 *}$, XING-BIN HU ${ }^{1}$, SHI-JIE MU ${ }^{1}$, \\ QUN-XING AN ${ }^{1}$, ZHI-XIN LIU ${ }^{1}$ and XIAN-QING ZHANG ${ }^{1}$ \\ ${ }^{1}$ Department of Blood Transfusion, Xijing Hospital, Fourth Military Medical University, Xi'an, Shaanxi 710032; \\ ${ }^{2}$ School of Life Sciences and Technology, Xidian University, Xi'an, Shaanxi 710071, P.R. China
}

Received September 10, 2012; Accepted October 16, 2012

DOI: $10.3892 /$ br.2012.36

\begin{abstract}
The aim of this study was to examine the manner in which varying proportions of serum and red blood cells (RBC) in massive blood transfusion affect the survival rates of patients with severe blood loss. Massive transfusion (MT) was determined as receiving $\geq 10$ units of red blood cells in $24 \mathrm{~h}$. The electronic medical records and blood transfusion information for the period January, 2002 to December, 2011 of patients with MT were examined. Moreover, we calculated the ratio of blood components and examined their correlation with survival. In total, 1,658 patients underwent MT during the period 2002-2011, with an overall of 28,030 units RBC, accounting for $2.8 \%$ of the total blood transfusion. In conclusion, fixing blood-component ratios has the potential to help improve survival rate in MT.
\end{abstract}

\section{Introduction}

Severe trauma, hemorrhoea and major operation usually need massive blood transfusion or massive transfusion (MT), including blood exchange transfusion. MT is the replacement of large amount of blood, for example transfusion that is equal to a complete blood volume replacement over $24 \mathrm{~h}$ (1). MT has classically been defined as the administration of $>10$ units of red blood cells (RBC) in a 24-h period (2).

MT occurs in $1-3 \%$ of civilian trauma admissions $(3,4)$ and this specific subset of patients suffers a high mortality $(5,6)$. MT occurs in $10-15 \%$ of the most severely injured patients $(7,8)$. In most institutions, the most common reason for MT is trauma (9). MT is also frequently required as treatment

Correspondence to: Dr Xian-Qing Zhang, Department of Blood Transfusion, Xijing Hospital, Fourth Military Medical University, Xi'an, Shaanxi 710032, P.R. China

E-mail: zhangxq@fmmu.edu.cn

*Contributed equally

Key words: blood loss in trauma, massive transfusion, infusion proportion for severe hemorrhage in patients with gastrointestinal (GI) bleeding (10-12) and those undergoing surgery.

Several retrospective studies have demonstrated a survival benefit for bleeding trauma patients when transfused with an early high RBC:fresh frozen plasma (FFP) 1:1 ratio, in civilian as well as military settings (13-16). To promote the clinical treatment of MT, the present study aimed to explore the effective blood component transfusion ratio through a retrospective study of MT.

\section{Materials and methods}

Patient data. During the time period examined in the present study, i.e., 2002-2011, 1,658 patients received a MT. The patients comprised 902 men and 756 women, with a mean age of 52 years. The 7-day hospital mortality for patients who received a MT was $27.3 \% \mathrm{MT}$ was determined as receiving $\geq 10$ units of $\mathrm{RBC}$ in this study. A total of 28,030 units of RBC were received. The medical records and blood transfusion information for the period January 2002 to December 2011 of patients with MT were examined using a computer information management system and the electronic medical records of the hospital. The study was approved by the Ethics Review Board of the Fourth Military Medical University, Xi'an, Shaanxi, China. Prior written and informed consent was obtained from each patient.

Methods. The blood component ratio in MT was calculated and its correlation with survival rate was examined. Variables including age, gender, admission diagnosis and cause of MT, such as intra-abdominal and GI bleeding, surgery, trauma, cardiac surgery, as well as obstetrics and gynecology bleeding, as well as its correlation with the number of patients were calculated to establish a stepwise logistic regression model using the SPSS 13.0 software for analysis.

Statistical analysis. Data were presented as the mean \pm SD. $\mathrm{P}<0.05$ was considered statistically significant.

\section{Results}

During the time period examined in the present study, 2002-2011, 1,658 patients received a MT. The study comprised 
Table I. Comparison of the transfused blood products in patients with massive or various types of blood transfusion between 2002 and 2011.

Number of infusion (units)

\begin{tabular}{lcr} 
& $\begin{array}{c}\text { Patients with massive transfusion } \\
\text { Blood products }\end{array}(\%)$ & $\begin{array}{c}\text { Patients with various types of } \\
\text { blood transfusion }\end{array}$ \\
\hline Red blood cells & $28,030(2.8)$ & $1,001,071$ \\
$\begin{array}{l}\text { Freshly frozen } \\
\text { plasma }\end{array}$ & $17,040(4.2)$ & 405,714 \\
Platelet & $15,020(0.7)$ & $2,145,714$ \\
Cryoprecipitate & $1,110(13.1)$ & 8,473 \\
Total & $61,200(1.7)$ & $3,560,972$ \\
\hline
\end{tabular}

Table II. Demographic data of patients with massive transfusion.

\begin{tabular}{|c|c|c|c|c|c|c|c|}
\hline \multirow[b]{2}{*}{ Characteristics } & \multicolumn{2}{|c|}{ Total } & \multicolumn{2}{|c|}{ Non-survival group } & \multicolumn{2}{|c|}{ Survival group } & \multirow[b]{2}{*}{ P-value } \\
\hline & No. & $\%$ & No. & $\%$ & No. & $\%$ & \\
\hline Total & 1,658 & 100 & 410 & 27.7 & 1,248 & 72.3 & \\
\hline Age (mean, years) & 52 & & & & & & \\
\hline Gender & & & & & & & 0.069 \\
\hline Male & 902 & 54.4 & 290 & 70.7 & 675 & 54.1 & \\
\hline Female & 756 & 45.6 & 120 & 29.3 & 573 & 45.9 & \\
\hline Admission type & & & & & & & 0.001 \\
\hline Emergency & 776 & 46.8 & 220 & 53.7 & 510 & 40.9 & \\
\hline Non-emergency & 882 & 53.2 & 190 & 46.3 & 738 & 59.1 & \\
\hline \multicolumn{8}{|l|}{ Diagnosis of type } \\
\hline $\begin{array}{l}\text { Gastrointestinal } \\
\text { bleeding }\end{array}$ & 253 & 15.3 & 25 & 6.1 & 167 & 13.4 & 0.090 \\
\hline $\begin{array}{l}\text { Intra-abdominal } \\
\text { bleeding }\end{array}$ & 295 & 17.8 & 145 & 35.4 & 167 & 13.4 & $<0.001$ \\
\hline Major vascular injury & 227 & 13.7 & 65 & 15.9 & 170 & 13.6 & 0.597 \\
\hline Trauma & 223 & 13.4 & 65 & 15.9 & 171 & 13.7 & 0.597 \\
\hline Heart disease & 275 & 16.6 & 60 & 14.6 & 228 & 18.3 & 0.408 \\
\hline Liver disease & 105 & 6.3 & 30 & 7.3 & 85 & 6.8 & 0.801 \\
\hline Obstetric hemorrhage & 100 & 6.0 & 10 & 2.4 & 90 & 7.2 & 0.092 \\
\hline Plastic surgery & 45 & 2.7 & 0 & 0 & 45 & 3.6 & 0.067 \\
\hline Skin/soft tissue injury & 15 & 0.9 & 0 & 0 & 15 & 1.2 & 0.293 \\
\hline Other & 120 & 7.3 & 10 & 2.4 & 110 & 8.8 & 0.029 \\
\hline
\end{tabular}

902 men and 756 women, with a mean age of 52 years. The 7-day hospital mortality for patients who received a MT was $27.3 \%$. In our study, 28,030 units of RBC were received, accounting for $2.8 \%$ of the total blood transfusion during the observation period. Moreover, patients were also administered $4.2 \%$ of FFP, $0.7 \%$ of blood platelets (PLT) and $13.1 \%$ of the entire cryoprecipitate usage in MT (Table I).

Baseline demographic data comparing survivors and non-survivors in the MT group are presented in Table II. In all diseases, patients receiving MT showed a higher survival rate compared with patients succumbing to various diseases. Additionally, a higher survival rate was detected in male compared to female patients. The ratio and amount of various blood components used in the survivors and non-survivors are shown in Table III. The median of FFP and RBC was 0.63 , and 0.73 and 0.58 in the non-survivors and survivors, respectively. Similarly, the median of PLT and RBC was 0.64 in the non-survivors, and 0.57 in the survivors. To explore the correlation between the survival rate and blood component, FFP:RBC were divided into three levels: $>1.2$ was the high 
Table III. Blood products used in patients with massive transfusion.

\begin{tabular}{|c|c|c|c|c|c|}
\hline \multirow[b]{2}{*}{ Blood products } & \multicolumn{2}{|c|}{ Non-survival group } & \multicolumn{2}{|c|}{ Survival group } & \multirow[b]{2}{*}{ P-value } \\
\hline & Mean & Range & Mean & Range & \\
\hline $\mathrm{RBC}$ & 22.4 & $10-64$ & 15.3 & $10-75$ & $<0.001$ \\
\hline FFP & 15.7 & $0-91$ & 9.2 & $0-34$ & $<0.001$ \\
\hline PLT & 13.0 & $0-17$ & 8.4 & $0-45$ & 0.003 \\
\hline Cry & 0.7 & $0-8$ & 0.9 & $0-18$ & 0.573 \\
\hline \multicolumn{6}{|l|}{ Ratio } \\
\hline FFP:RBC & 0.73 & $0-2.9$ & 0.58 & $0-2.4$ & 0.034 \\
\hline PLT:RBC & 0.64 & $0-2.4$ & 0.57 & $0-2.5$ & 0.421 \\
\hline Cry:RBC & 0.05 & $0-0.8$ & 0.05 & $0-0.9$ & 0.943 \\
\hline
\end{tabular}

RBC, red blood cells; FFP, fresh frozen plasma; PLT, platelets; Cry, cryoprecipitate.

Table IV. Comparison between the ratio of blood products used in patients with massive transfusion.

\begin{tabular}{|c|c|c|c|c|c|c|}
\hline \multirow[b]{2}{*}{ Blood products } & \multicolumn{2}{|c|}{ Total } & \multicolumn{2}{|c|}{ Non-survival group } & \multicolumn{2}{|c|}{ Survival group } \\
\hline & No. & $\%$ & No. & $\%$ & No. & $\%$ \\
\hline \multicolumn{7}{|l|}{ FFP:RBC ratio } \\
\hline High $(>1.2)$ & 278 & 16.8 & 100 & 24.4 & 133 & 10.7 \\
\hline Equal (0.8-1.2) & 200 & 12.1 & 50 & 12.2 & 195 & 15.6 \\
\hline Low $(<0.8)$ & 1,180 & 71.1 & 260 & 63.4 & 920 & 73.7 \\
\hline \multicolumn{7}{|l|}{ PLT:RBC ratio } \\
\hline $\operatorname{High}(>1.2)$ & 203 & 12.2 & 50 & 12.2 & 105 & 8.4 \\
\hline Equal (0.8-1.2) & 195 & 11.8 & 45 & 11.0 & 63 & 5.0 \\
\hline Low $(<0.8)$ & 1,260 & 76.0 & 315 & 76.8 & 1,080 & 86.6 \\
\hline Total & 1,658 & 100.0 & 410 & 100.0 & 1,248 & 100.0 \\
\hline
\end{tabular}

FFP, fresh frozen plasma; RBC, red blood cells; PLT, platelets.

value group; 0.8-1.2 was the equal group and $<0.8$ was the low group (Table IV).

\section{Discussion}

Timely and adequate blood transfusion to patients with blood loss is extremely significant. However, due to the coagulation disorders, hypothermia, acidosis and additional complications associated with blood transfusion, the clinical mortality rate remains high. MT in trauma patients affects a small percentage of civilian and military trauma patients, a great number of whom is expected to succumb to the disease early in their course from hemorrhage and to consume a great deal of trauma center resources $(13,17-24)$.

In their study, Riskin et al (25) suggested that implementation of a MT protocol and fixed blood component ratio are associated with reduced mortality. Trauma is a public health problem that draws worldwide attention and ranks third, following heart and cancer disease as the leading cause of mortality. In trauma patients, traumatic blood loss accounted for $40 \%$ of deaths, followed by traumatic brain injury (26). For patients with large blood loss, MT is one of the main treatment options. However, large importation of red blood cell suspension would dilute the clotting factors, which leads to coagulation disorders and further trauma-induced aggravated acidosis and hypothermia (27). Traumatic coagulopathy markedly affects patient survival rate. The $24-\mathrm{h}$ mortality rate in patients with trauma coagulopathy was demonstrated to be eight times more compared to other patients (28), while the overall mortality rate was four times more. Wafaisade et al (29) found that the survival rate improves significantly in patients with a FFP:RBC ratio of $>1: 1$. However, Sperry et al (16) found that the infusion of FFP and RBC improved the survival rate at a ratio of 1:1.5.

The most appropriate transfusion amount of plasma, platelet and cryoprecipitation and volume of other coagulation factors and $\mathrm{RBC}$ remain unknown, but the ratio of RBC:FFP:PLT has recently been identified as 1:1:1. While previous studies 
suggest that the FFP:RBC ratio is a significant variable, its importance has yet to be fully elucidated. Additional studies used a computer model to assess the outcome of blood transfusion management, indicating that the optimal ratio of FFP:RBC and PLT:RBC are 2:3 and 8:10, respectively (30).

We recommend a fixed ratio of RBC:FFP:PLT at 1:1:1. In his study, Johansson (31) concluded that the optimal transfusion by proper monitoring improved the survival of massively bleeding patients. At present, MT delivers blood products at a certain ratio, as well as order and time intervals. Recent studies have found that early detection of coagulation, early and active intervention of blood component proportion is extremely significant in patients with severe trauma. MT of almost whole blood markedly reduces mortality (32). Therefore, fixed blood component ratios improve the use of blood components and reduce mortality.

\section{References}

1. Roback JD, Combs MR, Grossman BJ and Hillyer CD (eds): Technical Manual. 16th edition. Bethesda MD: America Association of Blood Banks, pp148-152, 2008.

2. Malone DL, Hess JR and Fingerhut A: Massive transfusion practices around the globe and a suggestion for a common massive transfusion protocol. J Trauma 60: S91-S96, 2006.

3. Peng R, Chang C, Gilmore D and Bongard F: Epidemiology of immediate and early trauma deaths at an urban Level I trauma center. Am Surg 64: 950-954, 1998.

4. Malone DL, Dunne J, Tracy JK, Putnam AT, Scalea TM and Napolitano LM: Blood transfusion, independent of shock severity, is associated with worse outcome in trauma. J Trauma 54: 898-905, 2003.

5. Cinat ME, Wallace WC and Nastanski F: Improved survival following massive transfusion in patients who have undergone trauma. Arch Surg 134: 964-968, 1999.

6. Huber-Wagner S, Qvick M, Mussack T, et al: Working Group on Polytrauma of German Trauma Society (DGU). Massive blood transfusion and outcome in 1062 polytrauma patients: a prospective study based on the Trauma Registry of the German Trauma Society. Vox Sang 92: 69-78, 2007.

7. Gonzalez EA, Moore FA, Holcomb JB, et al: Fresh frozen plasma should be given earlier to patients requiring massive transfusion. J Trauma 62: 112-119, 2007.

8. Nunez TC, Voskresensky IV, Dossett LA, Shinall R, Dutton WD and Cotton BA: Early prediction of massive transfusion in trauma: simple as ABC (assessment of blood consumption)? J Trauma 66: 346-352, 2009.

9. Harvey MP, Greenfield TP, Sugrue ME and Rosenfeld D: Massive blood transfusion in a tertiary referral hospital. Clinical outcomes and haemostatic complications. Med J Aust 163: 356-359, 1995.

10. Hearnshaw S, Travis S and Murphy M: The role of blood transfusion in the management of upper and lower intestinal tract bleeding. Best Pract Res Clin Gastroenterol 22: 355-371, 2008.

11. Forcione DG, Alam HB and Kalva SP: Case records of the Massachusetts General Hospital. Case 9-2009. An 81-year-old man with massive rectal bleeding. N Engl J Med 360: 1239-1248, 2009.

12. Maltz GS, Siegel JE and Carson JL: Hematologic management of gastrointestinal bleeding. Gastroenterol Clin North Am 29: 169-187, 2000.
13. Borgman MA, Spinella PC, Perkins JG, et al: The ratio of blood products transfused affects mortality in patients receiving massive transfusions at a combat support hospital. J Trauma 63: 805-813, 2007.

14. Gunter OL Jr, Au BK, Isbell JM, Mowery NT, Young PP and Cotton BA: Optimizing outcomes in damage control resuscitation: identifying blood product ratios associated with improved survival. J Trauma 65: 527-534, 2008.

15. Maegele M, Lefering R, Paffrath T, et al: Red blood cell to plasma ratios transfused during massive transfusion are associated with mortality in severe multiply injury: a retrospective analysis from the Trauma Registry of the Deutsche Gesellschaft für Unfallchirurgie. Vox Sang 95: 112-119, 2008.

16. Sperry JL, Ochoa JB, Gunn SR, et al: An FFP:PRBC transfusion ratio $>/=1: 1.5$ is associated with a lower risk of mortality after massive transfusion. J Trauma 65: 986-993, 2008.

17. Acosta JA, Yang JC, Winchell RJ, et al: Lethal injuries and time to death in a level I trauma center. J Am Coll Surg 186: 528-533, 1998.

18. Schreiber MA, Perkins J, Kiraly L, Underwood S, Wade C and Holcomb JB: Early predictors of massive transfusion in combat casualties. J Am Coll Surg 205: 541-545, 2007.

19. Como JJ, Dutton RP, Scalea TM, Edelman BB and Hess JR: Blood transfusion rates in the care of acute trauma. Transfusion 44: 809-813, 2004.

20. Holcomb JB: Damage control resuscitation. J Trauma 62: S36-S37, 2007.

21. Sauaia A, Moore FA, Moore EE, et al: Epidemiology of trauma deaths: a reassessment. J Trauma 38: 185-193, 1995.

22. Spinella PC, Perkins JG, Grathwohl KW, et al: 31 st CSH Research Working Group. Fresh whole blood transfusions in coalition military, foreign national, and enemy combatant patients during Operation Iraqi Freedom at a U.S. combat support hospital. World J Surg 32: 2-6, 2008.

23. Dutton RP, Lefering R and Lynn M: Database predictors of transfusion and mortality. J Trauma 60 (Suppl 6): S70-S77, 2006.

24. Hoyt DB, Bulger EM, Knudson MM, et al: Death in the operating room: an analysis of a multi-center experience. J Trauma 37: 426-432, 1994.

25. Riskin DJ, Tsai TC, Riskin L, et al: Massive transfusion protocols: the role of aggressive resuscitation versus product ratio in mortality reduction. J Am Coll Surg 209: 198-205, 2009.

26. Hess JR, Holcomb JB and Hoyt DB: Damage control resuscitation: the need for specific blood products to treat the coagulopathy of trauma. Transfusion 46: 685-686, 2006.

27. MacLeod JB, Lynn M and McKenney MG: Early coagulopathy predicts mortality in trauma. J Trauma 55: 39-44, 2003.

28. Maegele M, Lefering R, Yucel N, et al: Early coagulopathy in multiple injury: an analysis from the German Trauma Registry on 8,724 patients. Injury 38: 298-304, 2007.

29. Wafaisade A, Maegele M, Lefering R, et al: High plasma to bed blood cell ratios are associated with lower mortality rates in patients receiving multiple transfusion $(4<$ red blood cell units $<10$ ) during acute trauma resuscitation. J Trauma 70: 81-89, 2011.

30. Hirshberg A, Dugas M, Banez EI, Scott BG, Wall MJ Jr and Mattox KL: Minimizing dilutional coagulopathy in exsanguinating hemorrhage: a computer simulation. J Trauma 54: 454-463, 2003.

31. Johansson PI: The blood bank: from provider to partner in treatment of massively bleeding patients. Transfusion 47: 176S-181S, 2007.

32. Shaz BH, Dente CJ and Harris RS: Transfusion management of trauma patients. Anesth Analg 108: 1760-1768, 2009. 